\title{
Perforated Mesenteric Cyst with Sepsis and Neurological Complication in a 9 Month Old Child
}

Mandal $\mathrm{KC}^{1}$, Saha $\mathrm{D}^{2}$, Halder $\mathrm{P}^{3^{*}}$, Chakraborty $\mathrm{P}^{3}$, Debnath $\mathrm{B}^{1}$, Mukhopadhyay $\mathrm{B}^{4}$

${ }^{1}$ Department of Pediatric Surgery, Dr. B.C.Roy, Post Graduate Institute of Pediatric Sciences (PGIPS), Kolkata 54, West Bengal, India

${ }^{2}$ Department of Pediatric Medicine, Dr. B.C.Roy, Post Graduate Institute of Pediatric Sciences (PGIPS), Kolkata 54, West Bengal, India

${ }^{3}$ Department of Pediatric Surgery, R. G. Kar Medical College \& Hospital, Kolkata, India

${ }^{4}$ Senior Consultant Pediatric Surgeon, Apollo Gleneagles Hospital, Kolkata, India

Corresponding Author: Pankaj Halder, MS, M.Ch

Address: Saroda pally, Baruipur, Kolkata-700144, West Bengal, India; Tel: +09231798777; E-mail: pankaj.cnmc@gmail.com

Received date: 24 January 2020; Accepted date: 17 February 2020; Published date: 25 February 2020

Citation: Mandal KC, Saha D, Halder P, Chakraborty P, Debnath B, Mukhopadhyay B. Perforated Mesenteric Cyst with Sepsis and Neurological Complication in a 9 Month Old Child. Asp J Pediatrics Child Health. 2020 Feb 25;2(1):30-33.

Copyright (C) 2020 Mandal KC, Saha D, Halder P, Chakraborty P, Debnath B, Mukhopadhyay B. This is an openaccess article distributed under the Creative Commons Attribution License, which permits unrestricted use, distribution, and reproduction in any medium provided the original work is properly cited.

\section{Abstract}

Mesenteric cyst is presented as lump abdomen or detected incidentally in ultrasonography for other reason or when it becomes symptomatic due to complications. Spontaneous infection or rupture of the mesenteric cyst and disseminated infections are very rare complications in children. Expeditious diagnosis and surgical excision of the cyst are imperative for fruitful outcome. We report a case of a perforated mesenteric cyst with sepsis and intracerebral haemorrhage in a 9 month child who was managed successfully in our institute.

\section{Keywords}

Mesenteric Cyst; Infection; Ruptured; Marsupialisation; Sepsis; Intracerebral Hemorrhage

\section{Introduction}

Mesenteric cyst (MC) is rare benign tumor, occurring more in pediatric population (1 per 20,000) than adult (1 per 140,ooo) and more in male than female [1]. They become symptomatic only in $25 \%$ of cases mainly due to mass effects or complications (infection/ perforation/ rupture). Successful management of complicated cyst depends largely on making a prompt diagnosis and treatment. Complete cyst excision either by open or laparoscopic techniques or partial excision of the cyst with marsupialisation of residual cyst cavity is the recommended treatment [2]. We present a case of 9-month old child with an infected and ruptured MC who underwent partial excision of the cyst and marsupialisation of the remaining part along with review of recent literature.

\section{Case Report}

A 9 month old male baby presented with fever and abdominal distention. He had a history of bowel obstruction for 3 days and passing scanty urine for 1 day. On clinical examination we found pulse-134/min, respiratory rate $-46 / \mathrm{min}$, blood pressure $-74 / 54 \mathrm{~mm}$ 
Citation: Mandal KC, Saha D, Halder P, Chakraborty P, Debnath B, Mukhopadhyay B. Perforated Mesenteric Cyst with Sepsis and Neurological Complication in a 9 Month Old Child. Asp J Pediatrics Child Health. 2020 Feb 25;2(1):30-33.

of $\mathrm{Hg}\left(<5 \mathrm{O}^{\text {th }}\right.$ percentile), temp-38.9 Celsius with cold clammy extremities. His abdomen was hugely distended, tense and tender in addition to rigidity and rebound tenderness. Intestinal peristaltic sound was absent and rectum was empty. Straight $\mathrm{X}$ ray abdomen showed opaque right half of the abdomen and intestine was concentrating on left side. A provisional diagnosis of peritonitis with shock was made.

The baby was resuscitated in pediatric intensive care unit (PICU) in the form of nasogastric tube suction and infusion of normal saline bolus $(20 \mathrm{ml} / \mathrm{kg}$ each 2 boluses) in addition to intravenous antibiotics and infusion of Dopamine (10mcg/kg/min). Simultaneously $\mathrm{Hb} \%$, TC, DC, Platelet, serum electrolytes, ABG and blood culture were performed. Ultrasonography (USG) of whole abdomen showed huge multiseptate cystic lesion which was extending from epigastrium to pelvis and compressing the pancreas and displacing gut loops to other site. Contrast enhance computed tomography (CECT) showed large peripherally enhancing abdomino pelvic cystic lesion with internal septations (Fig-1).

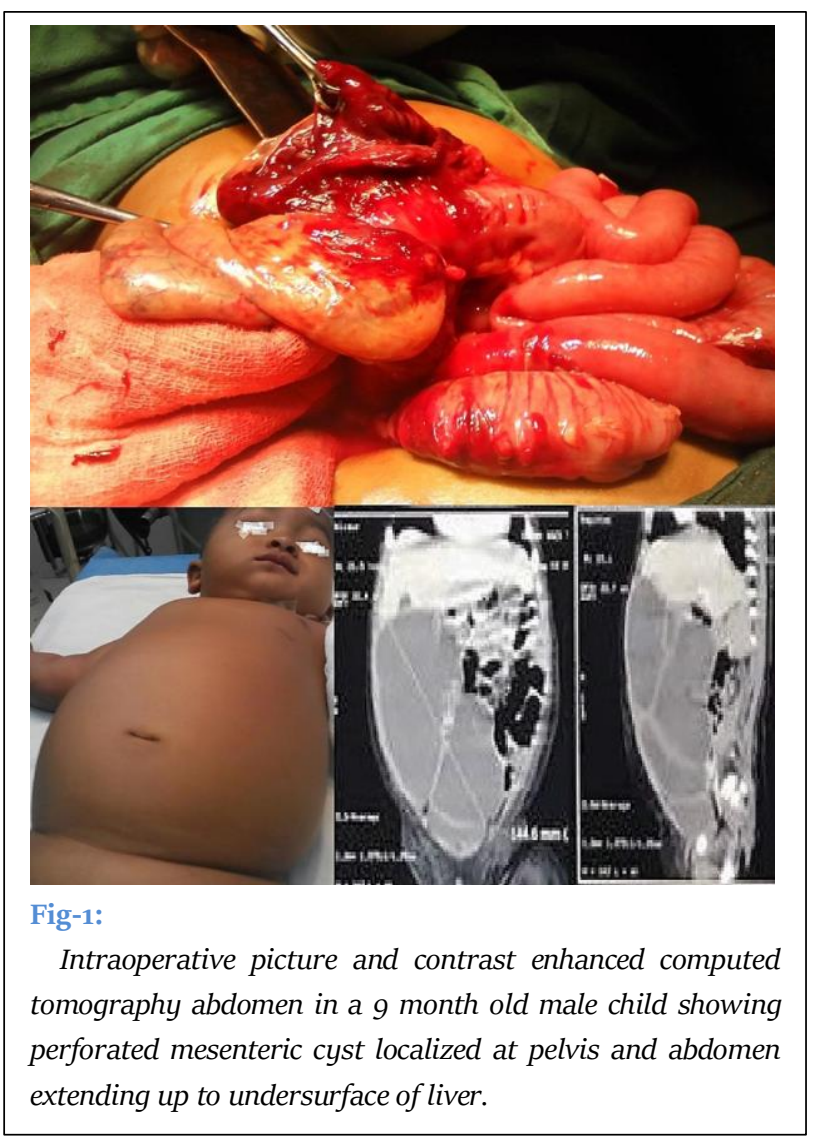

We resuscitated the baby and prepared him for exploratory laparotomy.

On exploration we found an infected and perforated MC arising from retroperitoneum inbetween stomach and transverse colon and part of the cyst traversing beyond transverse mesocolon. We could not excise the cyst completely even after resection of a part of the transverse colon. Marsupialisation was done for the remaining portion

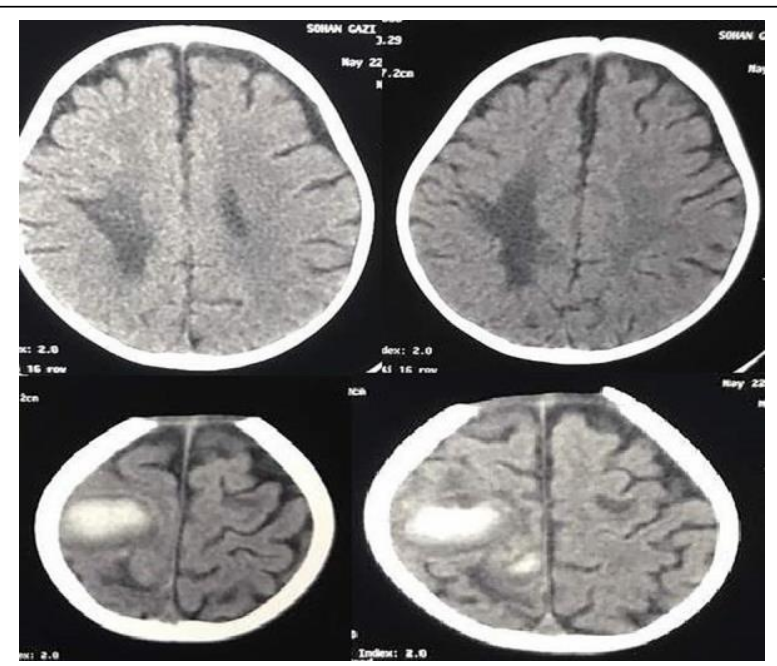

Fig-2:

Computed tomography of brain in a postoperative case of perforated mesenteric cyst suggested acute intracerebral hemorrhage in the right parietal region without midline shifting.

between aorta and IVC. After peritoneal lavage with warm normal saline, a double barrel right transverse colostomy was fashioned. The baby was shifted to PICU for postoperative care. On $2{ }^{\text {nd }}$ postoperative day (POD), the child developed focal convulsion involving left side of face, left hand and left leg. CSF study was normal. Non-contrast CT of brain suggested acute intracerebral bleed in right parietal region without midline shifting (Fig-2). Anticonvulsant medications were added. Though, post-operative period was stormy but the patient was ultimately survived and discharged on1oth POD. The right transverse colostomy was reversed after 2 month of primary operation. Now the patient is doing well in 6 month follow up. Histopathological report of excised specimen showed fibrous tissue infiltrated with lymphocytes, plasma cells, neutrophils and eosinophils. Areas of necrosis were evident at places. 
Sample from the peritoneum showed fibrous tissue, adipocytes and lymphoid follicle formation. The features were consistent with the diagnosis of ruptured infected mesenteric cyst.

\section{Discussion}

The first case of MC was reported in the literature by Benevieni in 1507. It can occur in the mesentery of gastrointestinal tract from duodenum to rectum with or without retroperitoneal extension. MC has a lining endothelium or mesothelium which sometimes destroyed by the pressure effect of cyst fluid and or infection [3]. The precise etiopathogenesis of MC is still unclear. Gross proposed that insufficient communication between lymphatics channels leads to benign proliferation of ectopic lymphatics [4].

Most of the MC (75\%) are asymptomatic and incidentally detected on imaging for other reason or during surgery. Symptomatic cases have nonspecific presentations like; abdominal pain, distention, nausea vomiting, diarrhea, constipation, loss of weight and bowel/bladder obstruction [5]. Moreover, few cases (10\%) may come to emergency with an acute lifethreatening conditions because of acute intestinal obstruction, volvulus, intracystic hemorrhage, infection and rupture $[6,7,8]$. Our patient presented with features of peritonitis and shock. Spontaneous perforation is very rare but reported in literature [9]. Rupture of a giant cyst due to trauma is also reported [10]. A small cyst may even complicated by torsion and produce acute abdominal condition [11]. Perioperative venous thrombosis and pulmonary thromboembolism may be a sequelae of infected and or ruptured cyst [12]. In our case, the patient developed neurological symptoms due to intracerebral hemorrhage in the right parietal lobe. Fatal intracerebral hemorrhage is potentially caused by sepsis-associated encephalopathy or disseminated intravascular coagulation due to sepsis $[13,14]$.

Early diagnosis can be made by USG screening. MC appears in USG as a smooth, thin walled cyst, internal septations, and fluid content with sedimentations (if infected) [15]. CECT is required for detailed delineation and differentiation from pseudocyst or duplication cyst [16]. Complete excision of the cyst with or without bowel resection is the treatment of choice for MC. Sometimes, even after bowel resection, complete excision of the cyst may not be possible in approximately $10 \%$ of cases because of involvement of major vascular/vital structures [17]. In such situation, marsupialisation of the non-resectable portion of the cyst wall is a suitable option.

\section{Conclusion}

$\mathrm{MC}$ is a rare, benign intra-abdominal lesion but, should be considered in the differential diagnosis of any intra-abdominal lesion even it has no specific symptoms. The knowledge of this rare entity, early detection and prompt surgical management helps to avoid potentially life-threatening condition. Moreover, early diagnosis with modern investigation and laparoscopic excision offers best outcome of these entity.

\section{Conflicts of Interest}

None

\section{Acknowledgement}

Prof. Madhumita Mukhopadhyay [MD], Department of Pathology, Institute of Postgraduate Medical Education and Research (IPGMER), Kolkata, West Bengal, India.

Prof. Sanat Kumar Ghosh [MD], Principal, PGIPS, Kolkata, India.

\section{References}

[1] Mandal KC, Kumar R, Halder P, Mukhopadhyay M, Debnath B, Mukhopadhyay B.. Mesenteric Cyst in Children: 7 Year Experience from Tertiary Pediatric Care Institute in India. Int $\mathrm{J}$ Gen Med Surg 2019;3:120-24.

[2] Gafar AM, Batikheet MY. Surgical management for mesenteric cysts in pediatric patients: a single center experience Int Surg J. 2018;5:1217-21.

[3] Prakash A, Agrawal A, Gupta RK, Sanghvi B, Parelkar S. Early management of mesenteric cyst prevents catastrophes: a single centre analysis of 17 cases. Afr J Paediatr Surg. 2010 Sep-Dec;7(3):140-43. [PMID: 20859015]

[4] Kim EJ, Lee SH, Ahn BK, Baek SU. Acute abdomen 
Citation: Mandal KC, Saha D, Halder P, Chakraborty P, Debnath B, Mukhopadhyay B. Perforated Mesenteric Cyst with Sepsis and Neurological Complication in a 9 Month Old Child. Asp J Pediatrics Child Health. 2020 Feb 25;2(1):30-33.

\section{Case Report}

caused by an infected mesenteric cyst in the ascending colon: a case report. J Korean Soc Coloproctol. 2011 Jun;27(3):153-56. [PMID: 21829771]

[5] Barut I, Tarhan OR, Ciris M, Akdeniz Y, Bulbul M. Intestinal obstruction due a mesenteric cyst. Yonsei Med J. 2004;45:356-58.

[6] Sardi A, Parikh KJ, Singer JA, Minken SI. Mesenteric cysts. Am Surg. 1987;53:58-6o.

[7] Alwan MH, Eid AS, Alsharif IM. Retroperitoneal and mesenteric cysts. Singapore Med J. 1999 Mar;40(3):16o-64.

[8] Ghazimoghadam B, Rajaie S. Urinary retention due to mesenteric cyst: An extremely unusual presentation of a rare complication. Indian J Nephrol. 2008 Jan;18(1):24-25. [PMID: 20368917]

[9] Ozdoğan M. Acute abdomen caused by a ruptured spontaneously infected mesenteric cyst. Turk J Gastroenterol. 2004 Jun;15(2):120-21. [PMID: 15334326]

[10] Yormaz S, Yilmaz H, Alptekin H, Ece I, Sahin M. A rare cause of acute abdomen: Mesenteric cyst torsion. International Journal Of Advances In Case Reports. 2015;2:80-82.

[11] Yanar F, Agcaoglu O, Ozcinar B, Mete O, Gunay K. Rupture of a Giant Mesenterıc Cyst after a Penetrating Abdominal Trauma. Journal of case reports. 2014;4:95-99.

[12] Giannos A, Stavrou S, Goumalatsos N, Fragkoulidis G, Chra E, Argiropoulos D, Loutradis D, Drakakis P. Mesenteric cysts and mesenteric venous thrombosis leading to intestinal necrosis in pregnancy managed with laparotomy: a case report and review of the literature. J Med Case Rep. 2017 Jul 7;11(1):184.

[PMID: 28683785]

[13] Tong DM, Zhou YT. No Awakening in Supratentorial Intracerebral Hemorrhage Is Potentially Caused by Sepsis-Associated Encephalopathy. Med Sci Monit. 2017 Sep 13;23:440814. [PMID: 28900072]

[14] Baek HJ, Lee DH, Han KH, Kim YM, Kim H, Cho B, Lee I, Choi K, Yong H, Hong G. Fatal Intracranial Hemorrhage in a Patient with Disseminated Intravascular Coagulation associated with Sepsis. J Crit Care Med 2016;31:134-39.

[15] Chou YH, Tiu CM, Lui WY, Chang T. Mesenteric and omental cysts: an ultrasonographic and clinical study of 15 patients. Gastrointest Radiol. 1991 Fall;16(4):311-14. [PMID: 1936773]

[16] Hebra A, Brown MF, McGeehin KM, Ross AJ 3rd. Mesenteric, omental, and retroperitoneal cysts in children: a clinical study of 22 cases. South Med J. 1993 Feb;86(2):173-76. [PMID: 8434287]

[17] Kurtz RJ, Heimann TM, Holt J, Beck AR. Mesenteric and retroperitoneal cysts. Ann Surg. 1986 Jan;203(1):109-12. [PMID: 3942415] 